\title{
Erratum to: Growing microalgae as aquaculture feeds on twin-layers: a novel solid-state photobioreactor
}

\author{
Thomas Naumann • Zehra Çebi • Björn Podola • \\ Michael Melkonian
}

Published online: 16 March 2013

(C) Springer Science+Business Media Dordrecht 2013

Erratum to: J Appl Phycol

$$
\text { DOI 10.1007/s10811-012-9962-6 }
$$

In the sentence "With a surface productivity of $2 \mathrm{~g} \mathrm{~m}^{-2}$ day $^{-1}$ and a flow rate of $6 \mathrm{~L}^{-1}$ per meter TL module, approximately $1 \mathrm{kWh}$ is required for pumping to produce $1 \mathrm{~kg}$ of algal dry mass" the flow rate should include the time (in hours). The corrected sentence is shown below.

"With a surface productivity of $2 \mathrm{~g} \mathrm{~m}^{-2}$ day $^{-1}$ and a flow rate of $6 \mathrm{~L}^{-1} \mathrm{~h}^{-1}$ per meter TL module, approximately $1 \mathrm{kWh}$ is required for pumping to produce $1 \mathrm{~kg}$ of algal dry mass".

The online version of the original article can be found at http://dx.doi.org/ 10.1007/s10811-012-9962-6.

T. Naumann $\cdot$ Z. Çebi $\cdot$ B. Podola $(\bowtie) \cdot$ M. Melkonian Botanisches Institut, Lehrstuhl 1, Universität zu Köln, Biozentrum, Köln, Zülpicher Str. 47 b, 50674 Köln, Germany

e-mail: bpodola@uni-koeln.de 